\title{
KEBERGANTUNGAN TEMPERATUR PLASMA HIDROGEN DALAM TEKANAN RENDAH
}

\author{
Siti Nurul Alifah, Saktioto* \\ Jurusan Fisika FMIPA, Universitas Riau \\ *E-mail korespondensi: saktioto@yahoo.com
}

\begin{abstract}
The density and reaction rate values of plasma are physical quantities needed to produce plasma hydrogen. Both are needed to estimate the heat and the operating time of plasma generator. Density and reaction rate of plasma values are obtained by computational modeling using the continuity and Arrhenius equation. Five spesies of hydrogen are used in this research i.e electron, $\mathrm{H}_{2}, \mathrm{H}^{2+}, \mathrm{H}_{\text {and }} \mathrm{H}^{+}$. The pressure used was 9.7 mTorr and the temperature of electron used is higher than the temperatures of the hydrogen species. The temperatures scale used in high at 34812 Kelvin for electron and 9283.2 for other species. The study resulted that hydrogen gas can be plasma when it reaches the time span 3.8x10${ }^{7}$ second. The equilibrium conditions last for $10^{-3}$ second after the time limit be returned as plasma gas. The result of density for each species at range $10^{16}$ until $10^{18} \mathrm{~m}^{-3}$. The value of the fastest reaction rate equal to $7,3 \times 10^{53} \mathrm{~m}^{-3} \mathrm{~s}^{-1}$.
\end{abstract}

Keywords: Plasma hydrogen nonthermal, Density, Reaction rate, Plasma generator

\begin{abstract}
ABSTRAK
Nilai densitas dan laju reaksi plasma adalah besaran fisika yang dibutuhkan untuk memproduksi plasma hidrogen. Keduanya diperlukan agar jumlah energy panas dan waktu pengoperasian alat pembangkit plasma dapat diketahui. Nilai densitas dan laju reaksi plasma diperoleh dengan pemodelan komputasi menggunakan persamaan kontinuitas dan persamaan Arrhenius. Lima spesies hidrogen digunakan dalam penelitian ini, yaitu elektron, $\mathrm{H}_{2}, \mathrm{H}^{2+}, \mathrm{H}$ dan $\mathrm{H}^{+}$Tekanan yang digunakan sebesar 9.7 mTorr dan suhu elektron lebih tinggi daripada suhu spesies hidrogen yang lain. Suhu yang digunakan dalam skala yang tinggi yaitu 34812 kelvin untuk elektron dan 9283.2 untuk spesies lainnya. Hasil yang didapatkan adalah gas hidrogen dapat menjadi plasma ketika mencapai rentang waktu $3,8 \times 10^{-7}$ sekon. Kondisi kesetimbangan bertahan selama $10^{-3}$ sekon setelah melewati batas waktu kesetimbangan plasma akan kembali menjadi gas. Densitas untuk masing masing spesies didapatkan berkisar $10^{16}$ sampai $10^{18} \mathrm{~m}^{-3}$. Nilai laju reaksi yang paling cepat didapatkan sebesar 7,3 $\times 10^{53} \mathrm{~m}^{-3}$.
\end{abstract}

Kata Kunci : Plasma hidrogen nontermal, Densitas, Laju reaksi, Pembangkitan plasma

Diterima 03-09-2019 | Disetujui 30-09-2019 | Dipublikasi 31-10-2019

\section{PENDAHULUAN}

Plasma tekanan rendah telah digunakan dalam kehidupan sehari hari secara meluas terutama dibagian medis dan industri [1]. Plasma tekanan rendah memiliki keuntungan dibandingkan plasma tekanan atomsfir. Plasma tekanan rendah memiliki laju reaksi yang tinggi dengan daerah tumbukkan yang luas [2].
Penggunaan plasma yang semakin banyak membuat peneliti berusaha membangkitkan plasma dalam skala laboratorium [1]. Proses pembangkitan plasma dapat dilakukan dengan macam macam cara dan biasanya menggunakan gas gas mulia [3]. Salah satu jenis gas mulia tersebut adalah hidrogen.

Penggunaan gas gas mulia disebabkan karena sifat dari gas mulia itu sendiri yang mudah untuk terbakar dan bereaksi dengan zat 
lainnya. Pembangkitan plasma membutuhkan nilai densitas dan laju reaksi. Densitas digunakan untuk menghitung jumlah energi panas yang dibutuhkan dalam proses pembangkitan plasma sedangkan laju reaksi dibutuhkan untuk mengetahui waktu yang dibutuhkan untuk membangkitkan plasma. Densitas dan laju reaksi diketahui agar pengoperasian alat pembangkit plasma bisa dioptimalkan sehingga, selama proses pembangkitan tidak terjadi kontaminasi atau pencampuran plasma dengan zat zat lain yang ada disekitarnya [3].

Penentuan densitas dan laju reaksi plasma dengan menggunakan cara eksperimen dianggap tidak efesien karena membutuhkan waktu yang lama untuk mencari nilai yang membuat plasma dalam keadaan setimbang dan biaya yang cukup besar. Maka dari itu, penentuan nilai densitas dan laju reaksi dilakukan dengan cara komputasi dengan menggunakan metode Runge Kutta yang dimodelkan melalui software MATLAB (Matrix Laboratory). Persamaan yang digunakan adalah persamaan kontinuitas yang bergantung pada waktu dan persamaan Arrhenius.

Plasma berdasarkan temperatur dibagi atas plasma termal dan nontermal. Plasma termal adalah plasma yang mempunyai nilai temperatur elektron dan temperatur ion sama sedangkan plasma nontermal mempunyai nilai temperatur elektron yang lebih tinggi daripada ionnya [4]. Sebuah gas dikatakan plasma apabila terjadi kesetimbangan muatan negatif dan muatan positif. Kesetimbangan muatan ini disebut sebagai kuasinetral [4]. Plasma tekanan rendah sangat sulit untuk mempertahankan kesetimbangan, maka digunakan temperatur elektron yang lebih tinggi daripada temperatur ion.

Simulasi komputasi ini menggunakan nilai tekanan sebesar 1,3 Pascal (10 miliTorr) dengan nilai temperatur ion hidrogen sebesar 9283,2 Kelvin dan nilai temperatur elektron sebesar 34812 Kelvin.

\section{METODE PENELITIAN}

Reaksi kimia digunakan untuk menggambarkan keadaan dalam plasma. Reaksi kimia menunjukkan spesies hidrogen yang saling bertumbukkan dan menghasilkan spesies lain yang akan diubah menjadi plasma. Tumbukkan antar spesies plasma dipengaruhi nilai temperatur dan tekanan yang digunakan sehingga akan menghasilkan energi kinetik.

Reaksi kimia kinetik digambarkan dengan menggunakan persamaan kontinuitas untuk masing masing spesies seperti persamaan [2]: $\mathrm{dn} / \mathrm{dt}+\nabla(\mathrm{n} \mathrm{v})=\mathrm{S}$

pada saat kesetimbangan termodinamik tercapai nilai $\mathrm{n}$ konstan sehingga persamaan dinyatakan sebagai :

$\mathrm{dn} / \mathrm{dt}=\mathrm{S}$

Suatu reaksi dapat ditulis dalam bentuk [6]: $\mathrm{aA}+\mathrm{bB} \leftrightarrow \mathrm{cC}+\mathrm{dD}$

Tabel 1. Data reaksi plasma hydrogen.

\begin{tabular}{|c|c|c|c|c|}
\hline $\begin{array}{r}\text { No. } \\
\text { Reaksi }\end{array}$ & Reaksi & $\begin{array}{c}\alpha \\
\left(m^{3} s^{-1}\right)\end{array}$ & $\beta$ & $\begin{array}{c}\gamma \\
(\mathbf{K})\end{array}$ \\
\hline 1 & $\mathrm{H}+\mathrm{e}^{-} \rightarrow \mathrm{H}^{+}+\mathrm{e}^{-}+\mathrm{e}^{-}$ & $1,51 \times 10^{31}$ & $-3,0$ & 158000 \\
\hline-1 & \multicolumn{4}{|c|}{ Data reaksi balik tidak tersedia } \\
\hline 2 & $\mathrm{H}_{2}+\mathrm{e}^{-} \rightarrow \mathrm{H}+\mathrm{H}+\mathrm{e}^{-}$ & $2,23 \times 10^{12}$ & 0,5 & 46600 \\
\hline-2 & \multicolumn{4}{|c|}{ Data reaksi balik tidak tersedia } \\
\hline 3 & $\mathrm{e}^{-}+\mathrm{H}_{2} \rightarrow \mathrm{H}_{2}^{+}+\mathrm{e}^{-}+\mathrm{e}^{-}$ & $3,11 \times 10^{-14}$ & 0 & 219324 \\
\hline-3 & \multicolumn{4}{|c|}{ Data reaksi balik tidak tersedia } \\
\hline 4 & $\mathrm{e}^{-}+\mathrm{H}_{2} \rightarrow \mathrm{H}+\mathrm{H}^{+}+2 \mathrm{e}^{-}$ & $3,07 \times 10^{-16}$ & 0 & 203078 \\
\hline-4 & \multicolumn{4}{|c|}{ Data reaksi balik tidak tersedia } \\
\hline
\end{tabular}


sehingga nilai laju reaksi maju dan laju reaksi balik dapat kita hitung dengan persamaan :

$\mathrm{Rf}=\mathrm{kf}(\mathrm{nA}) \mathrm{a}(\mathrm{nB}) \mathrm{b}$

$\mathrm{Rr}=\mathrm{kr}(\mathrm{nC}) \mathrm{c}(\mathrm{nD}) \mathrm{d}$

Nilai koefisien laju reaksi diselesaikan dengan persamaan :

$\mathrm{k}=\mathrm{k}=\frac{\left(n_{\mathrm{L}}\right)^{2}\left(n_{D}\right)^{2}}{\left(n_{\mathrm{U}}\right)^{2}\left(n_{D}\right)^{2}}$

Persamaan Arrhenius digunakan untuk menggambarkan ketergantungan laju $\mathrm{k}$ (konstan) dari tumbukan pada temperatur absolut. Persamaan Arrhenius dibentuk seperti persamaan :

$\mathrm{k}=\mathrm{A} e^{\left(\frac{-E}{\mathrm{R}}\right)}$

modifikasi lain juga ditulis :

$\mathrm{k}=\alpha(T / 300)^{\beta} e^{\left(\frac{-\gamma}{T}\right)}$

Konstanta $\alpha, \beta$, dan $\gamma$ di dalam persamaan diatas disebut dengan parameter Arrhenius yang nilainya tergantung kepada data eksperimen dalam setiap reaksi. Reaksi yang digunakan dapat dilihat pada Tabel 1 .

Reaksi dibuat dan dibentuk dalam bentuk model kinetik kimia dan nilai nilai parameter Arrhenius diketahui. Reaksi dan nilai nilai tersebut dimasukkan kedalam pengkodean yang terdiri dari dua program utama dan dua program masukkan. Program masukkan bernama phycon.m dan nthdata.m pada lampiran 1 dan 2. Program phycon berisi nilai nilai fisika yang akan digunakan dalam penelitian seperti muatan listrik elektron dan konstanta Boltzmann sedangkan program nthdata.m berisi parameter Arrhenius $(\alpha, \beta$, dan $\gamma$ ) hidrogen non termal, nilai tekanan dan temperatur kinetik masing masing spesies hidrogen yang digunakan dalam penelitian.

Program masukkan diberi nama dlndt.m dan nthequilb.m. Program dlndt.m berisi fungsi dan persamaan untuk menentukan nilai laju reaksi plasma hidrogen nontermal sedangkan program nthequilb.m berisi fungsi dan persamaan yang akan digunakan untuk mengolah data nthdata.m sehingga nilai densitas plasma hidrogen nontermal pada kesetimbangan termodinamik tekanan rendah.
Keempat program tersebut di jalankan secara terpisah pada software MATLAB dengan menggunakan metode runge kutta yang mempunyai bentuk umum :

$$
\begin{aligned}
& \mathrm{yi}+1=\mathrm{yi}+\mathrm{h}(\mathrm{a} 1 \mathrm{k} 1+\mathrm{a} 2 \mathrm{k} 2+\ldots+\text { ankn }) \\
& \mathrm{k} 1=\mathrm{f}(\mathrm{xi}, \mathrm{yi}) \\
& \mathrm{k} 2=\mathrm{f}(\mathrm{xi}+\mathrm{p} 1 \mathrm{~h}, \mathrm{yi}+\mathrm{q} 11 \mathrm{k} 1 \mathrm{~h}) \\
& \mathrm{kn}=\mathrm{f}(\mathrm{xi}+\mathrm{pn}-1 \mathrm{~h}, \mathrm{yi}+\mathrm{qn}-1,1 \mathrm{k} 1 \mathrm{~h}+\ldots+\mathrm{qn}- \\
& 1, \mathrm{kn}-1 \mathrm{~h})
\end{aligned}
$$

\section{HASIL DAN PEMBAHASAN}

Nilai hasil densitas dan nilai laju reaksi dapat dilihat pada tabel 2 dan 3. Tabel 2 memperlihatkan nilai densitas plasma yang telah setimbang. Densitas elektron mengalami penurunan ketika mencapai kesetimbangan sedangkan keempat spesies lain mengalami kenaikkan. Penurunan dan kenaikkan ini disevavkan karena densitas banyaknya spesies tersebut dalam reaksi yang terjadi.

Tabel 2. Hasil nilai densitas plasma hidrogen nontermal.

\begin{tabular}{lll}
\hline Spesies & Densitas log & Densitas $\left(\mathbf{m}^{-3}\right)$ \\
\hline elektron & $10^{18.2661}$ & $1,8 \times 10^{18}$ \\
\hline $\mathrm{H}_{2}$ & $10^{17.0123}$ & $1,03 \times 10^{17}$ \\
\hline $\mathrm{H}$ & $10^{17.8766}$ & $7,53 \times 10^{17}$ \\
\hline $\mathrm{H}^{+}$ & $10^{17.0460}$ & $1,11 \times 10^{17}$ \\
\hline $\mathrm{H}_{2}^{+}$ & $10^{16.6479}$ & $4,44 \times 10^{16}$ \\
\hline
\end{tabular}

Kondisi kesetimbangan hanya terjadi pada plasma termal sedangkan plasma nontermal tidak bisa mencapai kondisi kesetimbangan. Plasma nontermal hanya dapat mencapai kondisi optimal saja dimaan nilai densitas baik dari elektron maupun gas hanya akan setimbang Coding phycon.m, dlndt.m, nthdata.m dan nthequilb.m dijalankan dan didapatkan waktu dan nilai densitas plasma hidrogen nontermal dalam kondisi kesetimbangan.

Gambar 1 adalah grafik hasil tentang kesetimbangan densitas plasma hidrogen 
nontermal. Kelima spesies plasma hidrogen memiliki kesetimbangan densitas yang berbeda. Gambar menunjukkan bahwa kesetimbangan densitas tercapai pada waktu 380 nanosekon. Hal ini menunjukkan bahwa plasma akan terbentuk setelah waktu 380 nanosekon atau setara dengan 3,8 x $10^{-7}$ sekon.

Proses kesetimbangan densitas berlangsung dan dapat ditemukan plasma dalam selang waktu ini namun, kesetimbangan ini hanya berlangsung selama 10-3 saja seperti yang ditunjukkan pada gambar 2. Kelima spesies

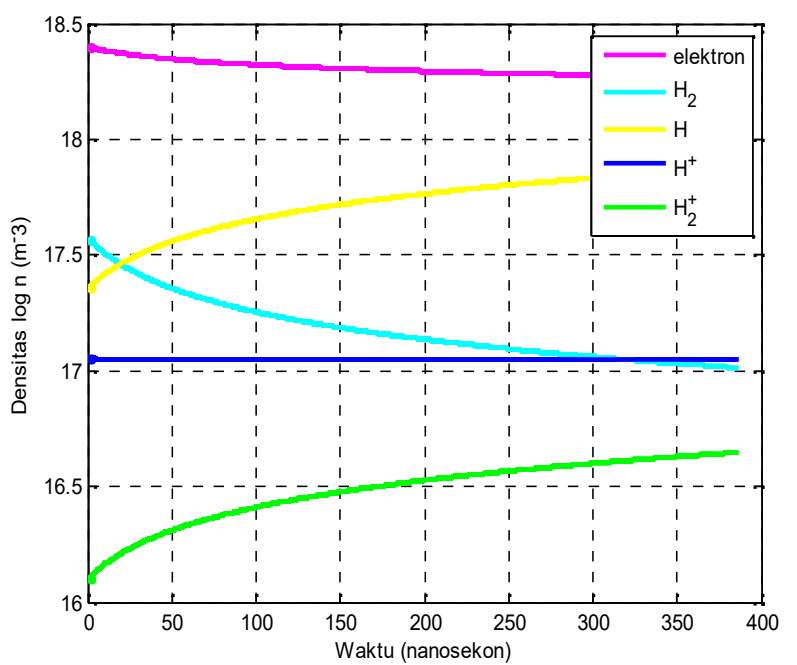

Gambar 1. Kesetimbangan densitas plasma hidrogen nontermal.

Nilai laju reaksi didepatkan dengan memasukkan reaksi pada coding nthdata.m kemudaian perasmaan laju reaksi pada coding yang berjudul nthdata.m akan diselesaikan oleh MATLAB dan nilai laju reaksi ditampilkan pada MATLAB melalui coding nthequilb.m. Semakin tinggi nilai laju reaksi maka nilai densitas juga akan semakin besar.

Nilai laju reaksi dipengaruhi oleh nilai $\alpha$ yang terdapat pada persamaan Arrhenius yang didapatkan berdasarkan hasil ekperimen oleh Mendes et al. tahun 2006 pada tabel 3.1. $\alpha$ adalah nilai cross section atau tampang melintang dari tumbukan yang terjadi pada suatu reaksi. Nilai cross section yang besar akan membuat suatu spesies dapat lebih mudah bertumbukan sehingga laju reaksi yang hidrogen mengalami perubahan densitas terhadap waktu.

Spesies $\mathrm{H}+$ adalah spesies yang paling cepat mencapai kesetimbangan densitas karena spesies tersebut telah berbentuk ion sedangkan keempat spesies lainnya harus mengalami proses ionisasi yang lebih lama untuk memecah partikel berat menjadi partikel yang lebih ringan kemudian akan diionisasi. Densitas plasma pada saat iterasi ke 400 tidak lagi mengalami perubahan sampai iterasi ke 1000 .

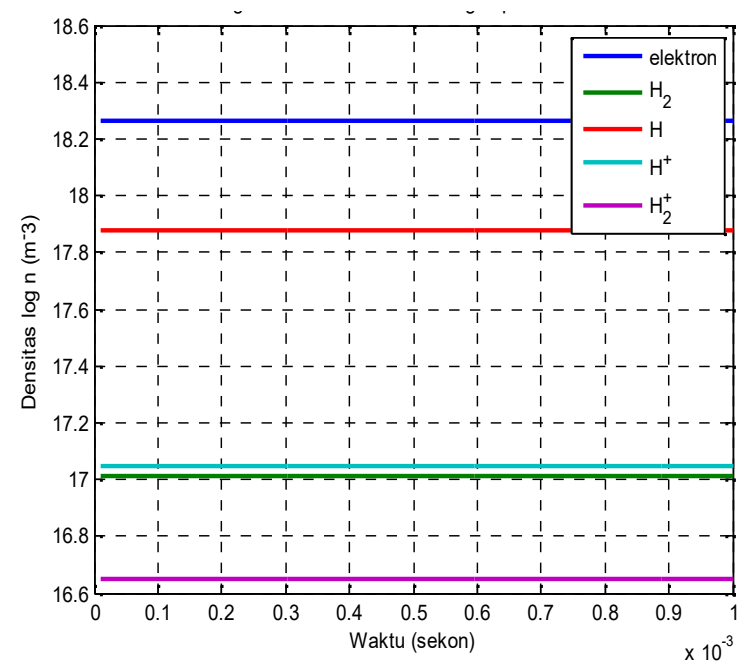

Gambar 2. Waktu kesetimbangan densitas plasma hidrogen nontermal.

terjadi akan semakin besar begitu pula sebaliknya [7].

Nilai $\beta$ adalah nilai yang memiliki hubungan dengan temperatur. Nilai $\beta=1$ maka semua atom hidrogen pada saat mencapai keadaan kesetimbangan akan hilang hal inilah yang menyebabkan nilai $\beta$ tidak pernah lebih dari 1. $\gamma$ adalah nilai energi aktivasi yang mempengaruhi nilai koefisien reaksi (k). Nilai $\mathrm{k}$ yang tinggi akan menyebabkan suatu reaksi memiliki nilai medan magnet dan medan listrik yang besar [7] namun ini tidak ditinjau dalam penelitian ini. Nilai laju reaksi pada tabel 4.3 dapat digunakan untuk membangkitkan plasma dalam skala laboratorium. 
Tabel 3. Daftar reaksi dan nilai laju reaksi plasma hidrogen nontermal

\begin{tabular}{|c|c|c|c|}
\hline $\begin{array}{r}\text { No. } \\
\text { Reaksi }\end{array}$ & Reaksi & $\begin{array}{l}\text { Laju Reaksi } \\
\qquad\left(\mathrm{m}^{-3} \mathrm{~s}^{-1}\right)\end{array}$ & Jenis Reaksi \\
\hline 1 & $\mathrm{H}+\mathrm{e}^{-} \rightarrow \mathrm{H}^{+}+\mathrm{e}^{-}+\mathrm{e}^{-}$ & $7,331 \times 10^{53}$ & Ionisasi \\
\hline-1 & \multicolumn{3}{|c|}{ Data reaksi balik tidak tersedia } \\
\hline 2 & $\mathrm{H}_{2}+\mathrm{e}^{-} \rightarrow \mathrm{H}+\mathrm{H}+\mathrm{e}^{-}$ & $3,836 \times 10^{46}$ & Disasosiasi \\
\hline-2 & \multicolumn{3}{|c|}{ Data reaksi balik tidak tersedia } \\
\hline 3 & $\mathrm{e}^{-}+\mathrm{H}_{2} \rightarrow \mathrm{H}_{2}^{+}+\mathrm{e}^{-}+\mathrm{e}^{-}$ & $7,992 \times 10^{11}$ & $\begin{array}{c}\text { Ionisasi } \\
\text { Disasosiasi }\end{array}$ \\
\hline-3 & \multicolumn{3}{|c|}{ Data reaksi balik tidak tersedia } \\
\hline 4 & $\mathrm{e}^{-}+\mathrm{H}_{2} \rightarrow \mathrm{H}+\mathrm{H}^{+}+2 \mathrm{e}^{-}$ & $4.540 \times 10^{10}$ & Ionisasi \\
\hline-4 & \multicolumn{3}{|c|}{ Data reaksi balik tidak tersedia } \\
\hline
\end{tabular}

\section{KESIMPULAN}

Penelitian telah berhasil dilakukan dan diperoleh kesimpulan. Kesimpulan yang diperoleh antara lain :

1. Pemodelan plasma hidrogen nontermal diperoleh nilai densitas setimbang pada tekanan rendah untuk spesies elektron, $\mathrm{H}$, $\mathrm{H} 2, \mathrm{H}+$ dan $\mathrm{H} 2+$ berturut turut dalam satuan m-3 adalah $1,8 \times 10^{18}, 7,53 \times 10^{17}$, $1,03 \times 10^{17}, 1,11 \times 10^{17}, 4,44 \times 10^{16}$. Rasio perbedaan nilai densitas elektron dan spesies yang lainnya dalam orde $10^{2}$ dimana nilai densitas untuk elektron pada plasma hidrogen nontermal tidak jauh berbeda dengan densitas spesies lainnya.

2. Laju reaksi yang dominan pada pemodelan plasma hidrogen nontermal ini adalah ionisasi. Laju reaksi terbesar dengan nilai $7,331 \times 10^{53}$ dan laju reaksi terkecil dengan nilai $4.540 \times 10^{10}$. elektron pada plasma hidrogen nontermal lebih banyak mengalami ionisasi sehingga densitasnya menurun dalam proses mencapai waktu optimal.

\section{REFERENSI}

1. Santos, M.A., Perito, R.C., Muzart,
J.L.R., Maliska, A.M. 2003. Plasma Dewaxing and Sintering of Compacted Unalloyed Iron. Materials Science Forum Vols. 416-418, 329.

2. Ismail, F.D., Saktioto, T., Fadhali, M., Yupapin, P.P., Qindeel, R., Ali, J. 2011. Thermodynamic Equilibrium of Nitrogen Species Discharge: Comparison with Global Model. Optik - International Journal for Light and Electron Optics 122 5, 455-458.

3. Yohannes, Hendra. 2013. Pemodelan Densitas Plasma Hidrogen pada Kesetimbangan Termodinamik Tekanan Atmosfer. Fakultas Matematika dan Ilmu Pengetahuan Alam Fisika Universitas Riau.

4. Bittencourt J.A. 2004. Fundamentals of Plasma Physics Third Edition. Springer Science: New York.

5. Saktioto. 2000. Studies of Atmospheric Pressure Plasma Sources Thesis. University of Manchester, Manchester.

6. Vojnovic, M., Popovic M., Ristic M.M., Vicic M.D., Popanic G.B., 2015. Rate Coefficients for Electro Impact Excitation of $\mathrm{N}_{2}$. Elsevier Journal Vols 463, 38-46. 